\title{
A NEW GENERAL BOAS-TYPE INEQUALITY AND RELATED CAUCHY-TYPE MEANS
}

\author{
A. ČIŽMEŠIJA, J. PEČARIĆ AND D. POKAZ
}

\begin{abstract}
We prove a new Boas-type inequality in a context of topological spaces and general $\sigma$-finite Borel measures. This enables us to introduce an one-parameter class of non-negative Boas differences and examine their properties, such as continuity and log-convexity. By proving the related Galvani's theorem and mean-value theorems of the Lagrange and Cauchy type we establish a new class of two-parameter Cauch-type means.
\end{abstract}

Mathematics subject classification (2010): Primary 26D10; Secondary 26D15.

Keywords and phrases: Boas inequality, Hardy-Littlewood average, Boas differences, Cauchy means.

\section{REFERENCES}

[1] N. I. Akhiezer, The classical moment problem and some related questions in analysis, Hafner Publishing Co., New York, 1965.

[2] M. Anwar, J. Pečarić, New means of Cauchy's type, J. Inequal. and Appl., 2008, Article ID 163202, 10 pages (electronic).

[3] R. P. Boas, Some integral inequalities related to Hardy's inequality, J. Anal. Math. 23 (1970), 53-63.

[4] P. S. Bullen, Handbook of Means and Their Inequalities, Kluwer Academic Publishers, Dordrecht/Boston/London, 2003.

[5] A. Čižmešija, S. Hussain, J. Pečarić, Some new refinements of strengthened Hardy and Pólya-Knopp's inequalities, J. Funct. Spaces Appl. 7, No. 2, (2009), 167-186.

[6] A. Cižmešija, J. Pečarić, L.-E. Persson, On strengthened Hardy and Pólya-Knopp's inequalities, J. Approx. Theory 125 (2003), 74-84.

[7] S. Hussain, J. Pečarić, Bounds for strengthened Hardy and Polya-Knopp's differences, Rocky Mountain J. Math 40, No. 3 (2010), 913-928.

[8] S. Kaijser, L.-E. Persson, A. Öberg, On Carleman and Knopp's Inequalities, J. Approx. Theory 117 (2002), 140-151.

[9] S. Levinson, Generalizations of an Inequality of Hardy, Duke Math. J. 31 (1964), 389-394.

[10] D. Luor, Modular inequalities for the Hardy-Littlewood averages, Math. Inequal. Appl. 13, No. 3 (2010), 635-642.

[11] D. S. Mitrinović, J. E. Pečarić, A. M. Fink, Classical and new inequalities in analysis, Kluwer Academic Publishers, Dordrecht/Boston/London, 1993.

[12] J. Xiao, $L^{p}$ and BMO Bounds of Weighted Hardy-Littlewood Averages, J. Math. Anal. Appl. 262 (2001), 660-666.

[13] E. Talvila, Necessary and Sufficient Conditions for Differentiating Under the Integral Sign, Amer. Math. Monthly, 108 (2001), 544-548. 